\title{
Tendências das pesquisas da Educação do Campo a partir da análise de publicações nos anais do ENPEC
}

\section{Trends in Field Education research from the analysis of publications in the annals of ENPEC}

\author{
Cristiane Silveira (cris_dpsilveira@hotmail.com) \\ Universidade Federal do Pampa (UNIPAMPA) \\ Ana Carolina Gomes Miranda (miranda.acg@ gmail.com) \\ Universidade Federal do Pampa (UNIPAMPA)
}

Resumo: O objetivo deste estudo foi identificar e analisar as principais tendências das pesquisas em Educação do Campo, publicados nos anais do Encontro Nacional de Pesquisa em Educação em Ciências (ENPEC), de todas as edições do evento entre 1997 e 2017, que abordam sobre o tema Educação do Campo. A investigação foi desenvolvida em quatro etapas: 1) Seleção dos artigos nos anais do ENPEC para estudo; 2) Coleta dos dados por meio do levantamento de artigos que abordam o tema; 3 ) Triagem a partir da leitura integral dos artigos encontrados e exclusão dos que não versam sobre o tema; 4) Análise dos artigos, que foi baseada nos seguintes critérios: Caracterização dos artigos, Aspectos metodológicos, Temática de investigação do artigo e Resultados das pesquisas. Ao total foram identificados 34 artigos e os resultados revelam: uma predominância de pesquisas procedentes de universidades que possuem o Curso de Educação do Campo há mais tempo; a maior parte dos artigos é de natureza empírica, com abordagem qualitativa e priorizam a Educação Superior; as temáticas de investigação mais utilizadas pelos autores dos artigos avaliados referem-se a "Formação inicial de professores", "Educação Ambiental" e "Processos de Ensino e Aprendizagem" voltada para uma abordagem freireana de educação. Com base na análise dos resultados apresentados nos artigos, este trabalho traz também algumas contribuições para as pesquisas na Educação do Campo.

Palavras-chave: Educação do Campo; Ensino de Ciências; Abordagem Temática; Agroecologia.

Abstract: The objective of this study was to identify and analyze the main trends of the field education research published in the annals of the National Encounter of Science Education Research (ENPEC), of all the editions of the event between 1997 and 2017, which deal with the theme Field Education. The examination was done in several stages: 1) Selection of articles in the annals of the ENPEC for study; 2) Data collection by means of the survey of articles that approach the subject; 3) Screening from the full reading of the articles found and exclusion from those that do not deal with the topic; 4) Analysis of the articles, which was based on the following criteria: Characterization of articles, Methodological aspects, Research topic of the article and Results of the research. A total of 34 articles were identified and the results were found: a predominance of studies coming from universities that have the Field Education Course 
for the longest time; the majority of the articles are empirical, qualitative approach and prioritize Higher Education; he most approached themes identified in the articles refer to "Initial Teacher Training", "Environmental Education" and "Teaching and Learning Processes", geared towards a Freirean approach to education. Based on the analysis of the results of the articles, this work also brings some contributions to the field education research.

Keywords: Field Education; Science Teaching; Thematic Approach; Agroecology.

\section{INTRODUÇÃO}

A luta pela educação do campo ganhou força a partir de 1997, através do I ENERA "Encontro Nacional de Educadores e Educadoras da Reforma Agrária", promovido pelo MST "Movimento dos Trabalhadores Rurais Sem Terra". No ano seguinte, aconteceu a "I Conferência Nacional por uma Educação Básica do Campo", que motivou essa população a defender políticas públicas de reforma agrária e a garantia à Educação do Campo de forma a promover a instrumentalização e o desenvolvimento de uma nova sociedade (CALDART et al., 2002, p. 11).

Ainda que os estudos sobre Educação do Campo possuam uma trajetória relativamente atual, considera-se relevante acompanhar sua evolução, identificando particularidades e tendências gerais dos trabalhos desenvolvidos nas diferentes áreas do conhecimento. A Educação do Campo tem ganhado espaço em eventos na área da Educação ao longo dos anos, reconhecendo que o aumento das pesquisas nesta área demonstra um avanço. Diante disso, sabe-se que o ENPEC "Encontro Nacional de Pesquisa em Educação em Ciências" é um evento nacional e têm muita visibilidade na Educação em Ciências. Desta forma, objetiva-se nesta investigação analisar e apresentar os resultados das linhas de pesquisas na Educação do Campo publicadas nos anais do ENPEC de todas as edições do evento (1997-2017), que abordam sobre o tema Educação do Campo, bem como analisar o que educadores e pesquisadores produzem sobre essa temática, buscando caracterizar os principais temas de investigação abordados neste evento. 
O ENPEC foi selecionado para análise por apresentar ampla representatividade e por ser um espaço relevante para debates sobre o Ensino das Ciências. Esse evento ocorre bianualmente e é promovido pela Associação Brasileira de Pesquisa em Educação em Ciências - ABRAPEC. Conforme informações disponíveis no site da ABRAPEC, o primeiro evento do ENPEC foi realizado em 1997, onde se criou um ambiente de divulgação e socialização de pesquisas desenvolvidas pela comunidade acadêmica, instituindo um espaço de interação de pesquisadores nas mais diversas áreas, tais como: Ambiental, Biologia, Química, Física, Geociências, Saúde e áreas afins, com a presença de discentes de pós-graduação, graduação e docentes.

Dentro deste contexto, a problemática que guiou essa pesquisa foi: “Quais são as principais tendências das pesquisas desenvolvidas na Educação do Campo?’. Diante disso, considera-se oportuno o desenvolvimento de estudos descritivos e analíticos que incidam sobre a produção acadêmica e versem sobre a Educação do Campo a fim de delinear as perspectivas e as tendências atuais das pesquisas desenvolvidas neste campo de estudo. Assim, o presente estudo possui como objetivo identificar as principais linhas de estudo da Educação do Campo, por meio da análise bibliográfica de Anais do ENPEC.

\section{EDUCAÇÃO DO CAMPO E SUAS INTERFACES}

No Brasil, a conquista de escolas do campo ganha força em meados século XX, através de reivindicação social, muitos trabalhadores campesinos lutavam pela existência das escolas no campo com a finalidade de incorporar a Educação Rural com ações de luta pela terra. Deste modo, o termo Educação Rural foi reformulada e surgiu Educação do Campo, que apresenta uma visão de produção de vida em diversos âmbitos, sendo estes: econômica, política, cultural e social (ENISWELER; KLIEMANN; STRIEDER, 2015, p.3).

Manifestando-se um novo conceito associado à Educação do Campo, entendendo que ele deve ser propício aos interesses e ao avanço sociocultural e econômico dos campesinos, que cumpra ás suas distinções históricas e culturais, com seu estilo de vida, método de trabalho e território (LUCAS, 2008, p.119). 
Para Souza e Reis (2003, p. 27):

O sentido da educação (...) está no fato de poder contribuir para que as pessoas assumam uma postura diante do meio em que convivem e de que, nessa busca do (re) conhecimento si (como sujeito histórico) e do lugar (como reflexo dessa história), possa intervir e transformar a ambos.

Evidencia-se uma premência de uma educação voltada para o campo, que possua metodologias e organização curricular que atenda às necessidades e trajetória dos povos do campo, considerando nesta nova perspectiva valorizar a sua cultura, estilo de vida. "A educação do Campo pode ocorrer tanto em espaços escolares quanto fora deles. Envolve saberes, métodos, tempos e espaços físicos diferenciados" (LOPES; LOURENÇO, 2015, p.6).

Segundo Rosa e Caetano (2008, p. 23):

\begin{abstract}
Com implantação do conceito "educação do campo", ocorre uma inclusão e consequente valorização das pessoas que habitam o meio rural, oferecendolhes oportunidade de participarem, por meio de suas experiências, de programas produtivos, atuando na sociedade de forma igualitária, estabelecendo uma relação harmoniosa entre produção, terra e seres humanos, com relações sociais democráticas e solidárias.
\end{abstract}

Foi através dos movimentos sociais, que houve reivindicações dos próprios movimentos de luta pela terra, motivando uma reorganização na educação direcionada ao campo, consolidando um novo artigo na Lei de diretrizes e Bases (LDB) 9394/96 Art. $28^{\circ}$, que ressalta o arranjo de conteúdos curriculares direcionados as competências e saberes específicos para estudantes do campo; organização escolar incluindo adequação do calendário escolar as condições climáticas e ciclo agrícola (BRASIL, 1996).

Neste contexto, a Educação do Campo teve que buscar metodologias diferenciadas para a construção do conhecimento, buscando agregar a experiência dos camponeses, sendo que, "Trata-se de uma demanda e de uma perspectiva de construção bem mais ampla do que simplesmente reconhecer o saber popular" (MOLINA, 2010 p.12). Sendo necessária a utilização de estratégias que atendam as demandas do campo já que, “[...] o campo tem sua singularidade, sua vida, e a educação no campo, portanto, não pode ser a mesma que da educação urbana, ainda que os conteúdos escolares venham ser os mesmos" (FREITAS, 2010, p. 158). Conforme Art. $5^{\circ}$ CNE/CEB/2002, 
em seu $\S 1^{\circ}$ a organização e funcionamento das escolas do campo respeitarão as diferenças e o direito a igualdade, considerando o estilo de vida, cultura, tradições (BRASIL, 2002).

Foi através da LDB e Diretrizes Curriculares para Educação Básica nas Escolas do Campo, instituídas pela Resolução CNE/CEB nº. 1, de 3 de abril de 2002, ressalva que a prática pedagógica deve relacionar a teoria com a prática vivenciada pelos estudantes, numa perspectiva integradora entre escola e sujeitos do campo (BRASIL, 2002).

Sabe-se, que por mais avanços que a legislação tenha dado ao longo dos anos, ainda assim as Escolas do campo encontram dificuldades para introduzir de forma eficiente em sala de aula, um ensino que atenda as especificidades dos povos do campo.

Desta forma, ressalta-se que para atuar na educação do campo, é necessário ir além de conteúdos e métodos sistematizados em bancos escolares. Requerem-se formas diversificadas e diferenciadas de abordagem desses conteúdos, necessitando de adequação a realidade do campo, pois o espaço rural não oferta as mesmas condições do espaço urbano, principalmente no que se refere ao alunado.

Os aspectos supracitados corroboram com as ideias de Caldart (2005), segundo a autora, é preciso repensar essa modalidade educacional organizando a prática educativa a partir do conhecimento prévio do espaço e dos alunos que são e serão atendidos no espaço rural. Além disso, a autora afirma que é extremamente importante rever outros seguimentos educacionais:

A organização do espaço pedagógico amplia-se para além da sala de aula, organizadas e desenvolvidas em diferentes espaços pedagógicos; 2- Educação do campo precisa ser pensada e exercida a partir de sua origem; 3- A vinculação do campo as políticas públicas e a educação; 4- A escola tem de levar em conta a história de cada educando e das lutas do campo; 5- Construir efetivamente, com todos os que vivem naquele local, naquele tempo concreto, outras formas de planejar, propor e executar as ações de desenvolvimento para que a vida possa ser vivida a seu tempo, com a criação de novas possibilidades; 6- Recriação da organização do trabalho e das práticas pedagógicas, baseadas em fundamentos que se coloquem desde as raízes destes povos 7- Aproximar-se tanto da cultura local, tendo em vista a realidade e o contexto onde vivem os (as) educandos (as) e suas famílias, quanto dos processos em andamento; 8- Implementação de novas ações que desenvolvam perspectivas e possibilidades nas relações da vida, do trabalho, das necessidades dos sujeitos envolvidos 9- A escolaridade dos povos do 
campo não dá conta de construir conceitos que lhes permita compreender o que realmente se passa no contexto. Neste caso o estudo poderá constituir-se de temas como: a história e o modelo de desenvolvimento implantado no Brasil, aspectos deste modelo vividos no local, como é o caso da agricultura e da educação; alguns fundamentos de Educação Popular; as relações de submissão e de dependência do campo brasileiro, bem como de outros temas que são considerados necessários para o processo (CALDART, 2005, p. 135).

Diante desta problemática, sentiu-se a necessidade de pesquisar sobre o que vem sendo investigado sobre a Educação do Campo, para delinear um campo de estudo que possa dar perspectivas e subsídios para que esses professores possam obter referenciais teóricos sobre metodologias que possam contribuir em suas aulas de Ciências.

\section{METODOLOGIA}

A metodologia utilizada neste trabalho caracteriza-se como uma pesquisa bibliográfica. Segundo Gil (2009), a pesquisa bibliográfica é realizada a partir do levantamento de referências teóricas, publicadas por meios escritos e eletrônicos, tais como livros, artigos científicos e páginas de web sites. $\mathrm{O}$ autor afirma que qualquer trabalho científico se inicia com uma pesquisa bibliográfica, permitindo ao pesquisador conhecer o que já se estudou sobre um determinado assunto.

Para Lakatos e Marconi (2001), a pesquisa bibliográfica:

[...] é desenvolvida a partir de material já elaborado, constituído, principalmente, de livros e artigos científicos e é importante para o levantamento de informações básicas sobre os aspectos direta e indiretamente ligados à nossa temática. A principal vantagem da pesquisa bibliográfica reside no fato de fornecer ao investigador um instrumental analítico para qualquer outro tipo de pesquisa, mas também pode esgotar-se em si mesma (LAKATOS e MARCONI, p. 53, 2001).

O principal objetivo de uma pesquisa bibliográfica é quantificar, identificar, analisar e descrever uma série de padrões na produção do conhecimento científico de determinado tema, neste caso a partir do levantamento de trabalhos que versam sobre Educação do campo. Para isso, realizou-se um levantamento dos artigos publicados sobre Educação do Campo nos Anais do ENPEC entre 1997 e 2017. Esse período foi delimitado em decorrência do primeiro evento até o último ocorrido, contemplando a produção bibliográfica sobre o assunto desenvolvido durante 20 anos. 
A investigação foi desenvolvida em quatro etapas:

1) Seleção dos artigos nos anais do ENPEC para estudo:

Foram selecionados artigos publicados nos anais do ENPEC que abordam o tema Educação do Campo. Esses artigos foram selecionados e classificados quanto às temáticas relacionadas a esse campo de estudo.

2) Coleta dos dados por meio do levantamento de artigos que abordam o tema:

A partir da seleção dos anais do ENPEC, foram realizadas buscas por artigos que abordam o tema em estudo, por meio dos seguintes termos: escola do campo, Educação do Campo, classe multisseriada, licenciatura em Educação do Campo, educação científica do campo e alunos do campo, no título, palavras-chave e resumo.

3) Triagem a partir da leitura integral dos artigos encontrados e exclusão dos que não versam sobre o tema:

Um considerável número de artigos foi localizado e a partir da leitura integral do texto das pesquisas foram descartados os trabalhos que não abordaram pesquisas na Educação do Campo. Ao final deste estágio, foram selecionados trinta e quatro artigos que versam sobre o tema.

4) Análise dos artigos:

Cada artigo foi lido e examinado a partir de um roteiro previamente elaborado (Anexo 1), que considerou os seguintes critérios de análises: Caracterização, Aspectos metodológicos, Temática de investigação do artigo e Resultados das pesquisas.

No que se refere à caracterização, foram analisados os artigos a partir das categorias: título, ano, instituição. A caracterização dos artigos contempla informações importantes, pois revela sua origem e período. Esses dados possibilitam avaliar as condições de produção por região e o acesso a pesquisas que estavam sendo produzidas no campo das produções científicas em determinado período (FERNANDES e CAMPOS, 2017). 
No critério Aspectos metodológicos, buscou-se descrever o perfil metodológico dos estudos, os quais foram analisados, por meio de categorias já descritas na literatura (COSTA E MOREIRA, 1996; HOPPEN e MEIRELES, 2005), tais como: i) Natureza da pesquisa; ii) Abordagem da pesquisa; iii) nível de ensino.

Em relação à categoria Natureza da pesquisa, os artigos foram classificados em teórico ou empírico. Segundo Demo (2000), as pesquisas teóricas são dedicadas a reconstruir a teoria, conceitos e aprimorar fundamentos teóricos. Já as pesquisas empíricas, dedicam-se ao tratamento experimental da realidade, produzem e analisam dados que conferem maior concretude as argumentações, principalmente pela aproximação prática.

A Abordagem da pesquisa refere-se aos métodos empregados pelos autores dos artigos referentes à coleta e análise dos dados. As publicações foram classificadas em:

- Pesquisa qualitativa, quando envolve análises descritivas que enfatizam a subjetividade do sujeito e possui o ambiente natural como fonte de dados;

- Pesquisa quantitativa, mensura os dados, por meio de métodos estatísticos e busca generalizar os resultados para uma determinada população estudada;

-Pesquisa mista, mescla os aspectos qualitativos e quantitativos.

Com relação ao Nível de ensino, os artigos foram classificados conforme as etapas da educação brasileira, que são: Ensino Fundamental $\left(1^{\circ}\right.$ ao $9^{\circ}$ ano $)$, Ensino Médio ( $1^{\mathrm{a}}, 2^{\mathrm{a}}$ e $3^{\mathrm{a}}$ série) e Ensino Superior.

No critério "Temática de Investigação dos artigos" foi identificada as tendências de pesquisa nos artigos analisados. Essa análise é importante porque permite avaliar e identificar os pressupostos teóricos assumidos pelos autores dos estudos e a sua pertinência para a pesquisa desenvolvida (FERNANDES e CAMPOS, 2017). Nesse critério as categorias emergiram a posteriori.

Por fim, o critério Resultados apresenta uma análise das contribuições dos artigos avaliados para a Educação do Campo. As categorias deste critério são emergentes ( $a$ posteriori). 


\section{RESULTADOS E DISCUSSÕES}

As análises dos artigos selecionados estão organizadas, conforme especificado na metodologia: “Caracterização”, “Aspectos metodológicos”, "Temática investigação do artigo"e "Resultados das pesquisas".

\subsection{Categoria: Caracterização}

Investigaram-se as onze edições do ENPEC, desde a primeira, ocorrida no ano de 1997 até a última em 2017. Foram encontrados no total nove mil e quarenta e seis artigos (9046), dentre eles, foram selecionados para análise trinta e quatro estudos (34) que versam sobre o tema Educação do Campo, conforme apresentado no Quadro1.

Quadro 1 - Título, ano, autores, temática dos artigos analisados em ordem cronológica.

\begin{tabular}{|c|c|c|c|}
\hline Título & Ano & Autores & Temática \\
\hline $\begin{array}{l}\text { 1-O ensino de ciências em classes } \\
\text { multisseriadas: uma abordagem de } \\
\text { ensino por temáticas de estudos }\end{array}$ & 2005 & $\begin{array}{l}\text { GONÇALVES, T. V. O.; } \\
\text { FREITAS, M. N. M. }\end{array}$ & Classe Multisseriada \\
\hline $\begin{array}{c}\text { 2-Educação ambiental no contexto da } \\
\text { educação para o campo: um saber } \\
\text { necessário }\end{array}$ & 2007 & CRIBB, S. L. de S. P. & Educação Ambiental \\
\hline $\begin{array}{l}\text { 3-Entre o exigido e o produzido: o } \\
\text { currículo escolar por professores de } \\
\text { ciências em escolas do campo }\end{array}$ & 2009 & $\begin{array}{l}\text { CARDOSO, L. de R.; } \\
\text { ARAUJO, M. I. O. }\end{array}$ & Currículo \\
\hline $\begin{array}{l}\text { 4-Formação de professores de ciências } \\
\text { nas licenciaturas em educação do } \\
\text { campo: uma experiência da faculdade de } \\
\text { educação da UFMG }\end{array}$ & 2009 & $\begin{array}{l}\text { VENÂNCIO, J. M. P.; LIMA, } \\
\text { M. E. C. C. }\end{array}$ & $\begin{array}{l}\text { Formação Inicial de } \\
\text { Professores }\end{array}$ \\
\hline $\begin{array}{c}\text { 5-Contextualização e educação } \\
\text { ambiental no ensino de química: } \\
\text { implicações na educação do campo }\end{array}$ & 2009 & $\begin{array}{l}\text { LINDEMANN, R. H.; } \\
\text { MARQUES, C. A. }\end{array}$ & Educação Ambiental \\
\hline $\begin{array}{l}\text { 6-O desenvolvimento do conceito } \\
\text { energia em um diálogo intercultural } \\
\text { entre as ciências e as vivências de } \\
\text { estudantes de licenciatura do campo }\end{array}$ & 2011 & $\begin{array}{l}\text { CREPALDE, R. dos S.; } \\
\text { JUNIOR, O. A. }\end{array}$ & $\begin{array}{l}\text { Processos de Ensino- } \\
\text { Aprendizagem }\end{array}$ \\
\hline $\begin{array}{l}\text { 7-Planejamento e desenvolvimento de } \\
\text { uma disciplina optativa na escola campo: } \\
\text { o estágio como espaço de construção de } \\
\text { saberes }\end{array}$ & 2011 & GONÇALVES, F. C. et al. & $\begin{array}{l}\text { Formação Inicial de } \\
\text { Professores }\end{array}$ \\
\hline $\begin{array}{c}\text { 8-Matemática e CTS: o ensino de } \\
\text { medidas de áreas sob o enfoque da } \\
\text { ciência tecnologia e sociedade em uma } \\
\text { escola do campo }\end{array}$ & 2011 & MIRANDA, C. T de. et al. & $\begin{array}{l}\text { Ciência tecnologia e } \\
\text { Sociedade }\end{array}$ \\
\hline $\begin{array}{l}\text { 9-Ecoletramento: } \mathrm{O} \text { ensino de ciências } \\
\text { na escola do campo }\end{array}$ & 2011 & $\begin{array}{c}\text { SILVA, C. R da; FREITAS, D. } \\
\text { de }\end{array}$ & Educação Ambiental \\
\hline $\begin{array}{l}\text { 10-Uma experiência de articulação entre } \\
\text { conhecimentos de uma disciplina de }\end{array}$ & 2011 & $\begin{array}{l}\text { TAVARES, M. de L.; } \\
\text { VALDARES, J. M.; }\end{array}$ & Formação Inicial de \\
\hline
\end{tabular}


Vol. 2, n. 2. Mai./Ago. 2019

\begin{tabular}{|c|c|c|c|}
\hline $\begin{array}{c}\text { biologia e outra de física do currículo de } \\
\text { um curso de licenciatura para o campo } \\
\text { com ênfase em ciências da vida e da } \\
\text { natureza (CVN) de uma Universidade } \\
\text { Federal Brasileira }\end{array}$ & & CREPALDE, R. dos S. & Professores \\
\hline $\begin{array}{l}\text { 11-Educação Ambiental: comparando } \\
\text { dados de uma escola urbana com uma } \\
\text { escola do campo }\end{array}$ & 2013 & $\begin{array}{l}\text { SILVEIRA, D. I.; JÚNIOR, A. } \\
\text { L.; FAGUNDES, M. C. V. }\end{array}$ & Educação Ambiental \\
\hline $\begin{array}{c}\text { 12-Palavra própria e palavra alheia: } \\
\text { análise de uma Questão Socialmente } \\
\text { Controversa numa turma de Licenciatura } \\
\text { do Campo }\end{array}$ & 2013 & $\begin{array}{l}\text { CREPALDE, R. dos S.; } \\
\text { JÚNIOR, O. G. A. }\end{array}$ & $\begin{array}{l}\text { Formação Inicial de } \\
\text { Professores }\end{array}$ \\
\hline $\begin{array}{l}\text { 13-A temática dos Agrotóxicos no } \\
\text { Ensino de Ciências: as compreensões de } \\
\text { estudantes da Licenciatura em Educação } \\
\text { do Campo }\end{array}$ & 2013 & $\begin{array}{l}\text { FERNANDES, C. dos S.; } \\
\text { STUANI, G. M. }\end{array}$ & $\begin{array}{l}\text { Processos de Ensino- } \\
\text { Aprendizagem }\end{array}$ \\
\hline $\begin{array}{l}\text { 14-Concepções de meio ambiente no } \\
\text { Projeto Político Pedagógico e nos Planos } \\
\text { de Ensino de professores de uma escola } \\
\text { do campo }\end{array}$ & 2013 & $\begin{array}{l}\text { LOPES, T. M.; ZANCUL, M. } \\
\text { C. de S. }\end{array}$ & Educação Ambiental \\
\hline $\begin{array}{c}\text { 15-O protagonismo dos camponeses e o } \\
\text { Ensino de Ciências nas escolas do } \\
\text { campo }\end{array}$ & 2015 & $\begin{array}{l}\text { CARCAIOLI, G. F.; TONSO, } \\
\text { S. }\end{array}$ & Educação Ambiental \\
\hline $\begin{array}{l}\text { 16-O Ensino de Ciências para os Alunos } \\
\text { do Campo: Implicações para Efetivação } \\
\text { do Direito a Educação Escolar }\end{array}$ & 2015 & $\begin{array}{l}\text { ALMEIDA, C. L. dos S.; } \\
\text { LARCHERT, J. M.; FILHO, N. } \\
\text { J. de G. }\end{array}$ & $\begin{array}{l}\text { Processos de Ensino- } \\
\text { Aprendizagem }\end{array}$ \\
\hline $\begin{array}{c}\text { 17-Formação de professores em } \\
\text { educação do campo: A educação sexual } \\
\text { em pauta }\end{array}$ & 2015 & $\begin{array}{l}\text { PARREIRAS, M. M. M.; } \\
\text { COUTINHO, F. A. }\end{array}$ & $\begin{array}{l}\text { Formação Inicial de } \\
\text { Professores }\end{array}$ \\
\hline $\begin{array}{l}\text { 18-Uma perspectiva interdisciplinar para } \\
\text { o curso de Educação do Campo na } \\
\text { Regional Goiás - UFG }\end{array}$ & 2015 & $\begin{array}{l}\text { CAMPOS, R. I.; SILVA, V. de } \\
\text { A.; FREITAS, E. C. de.; } \\
\text { MONTEIRO, H. S. R. }\end{array}$ & Currículo \\
\hline $\begin{array}{l}\text { 19-As potencialidades da abordagem } \\
\text { temática na formação de educadores do } \\
\text { campo e indígenas }\end{array}$ & 2015 & $\begin{array}{l}\text { STUANI, G. M.; } \\
\text { FERNANDES, C. dos S.; } \\
\text { YAMAZAKI, R. M. }\end{array}$ & $\begin{array}{l}\text { Formação Inicial de } \\
\text { Professores }\end{array}$ \\
\hline $\begin{array}{l}\text { 20-Elementos teórico-metodológicos } \\
\text { para a análise da materialidade dos } \\
\text { espaços formativos no âmbito da } \\
\text { Licenciatura em Educação do Campo }\end{array}$ & 2015 & $\begin{array}{l}\text { SILVA, A. P. da; COUTINHO, } \\
\text { F. A. }\end{array}$ & $\begin{array}{l}\text { Formação Inicial de } \\
\text { Professores }\end{array}$ \\
\hline $\begin{array}{l}\text { 21-Abordagem de temas no Ensino de } \\
\text { Ciências e Matemática: um olhar para } \\
\text { produções relacionadas à Educação do } \\
\text { Campo }\end{array}$ & 2017 & $\begin{array}{l}\text { HALMENSCHLAGER, K. R.; } \\
\text { FERNANDES, C. dos S.; } \\
\text { CAMILLO, J.; BRICK, E. M. }\end{array}$ & $\begin{array}{l}\text { Processos de Ensino- } \\
\text { Aprendizagem }\end{array}$ \\
\hline $\begin{array}{l}\text { 22-Estudos do Currículo e Educação do } \\
\text { Campo: Potencialidades reflexivas na } \\
\text { interface com a Educação em Ciências }\end{array}$ & 2017 & BRITTO, N. S.; PAITER, L. & Currículo \\
\hline $\begin{array}{l}\text { 23-A controvérsia agroecológica em } \\
\text { uma abordagem intercultural de } \\
\text { Educação Científica: a biodiversidade } \\
\text { nos discursos de licenciandos do campo }\end{array}$ & 2017 & SILVA, D. K.; KATO, D. S. & Educação Ambiental \\
\hline $\begin{array}{l}\text { 24-Agroecologia como matriz } \\
\text { pedagógica para o ensino de Ciências da } \\
\text { Natureza nas Licenciaturas em Educação }\end{array}$ & 2017 & $\begin{array}{l}\text { CARCAIOLI, G. F.; TONSO, } \\
\text { S.; NETO, W. M. }\end{array}$ & Educação Ambiental \\
\hline
\end{tabular}


Vol. 2, n. 2. Mai./Ago. 2019

\begin{tabular}{|c|c|c|c|}
\hline do Campo & & & \\
\hline $\begin{array}{l}\text { 25-A ideia de área de conhecimento: } \\
\text { contribuições para pensar a } \\
\text { peculiaridade da formação inicial nas } \\
\text { Licenciaturas em Educação do Campo } \\
\text { no Brasil }\end{array}$ & 2017 & $\begin{array}{c}\text { BRICK, E. M.; BORGES, M. } \\
\text { G. }\end{array}$ & $\begin{array}{l}\text { Formação Inicial de } \\
\text { Professores }\end{array}$ \\
\hline $\begin{array}{l}\text { 26-Estilos de pensamento sobre } \\
\text { natureza: um estudo com licenciandos } \\
\text { em educação do campo }\end{array}$ & 2017 & $\begin{array}{l}\text { PARREIRAS, M. M. M.; } \\
\text { COUTINHO, F. A. }\end{array}$ & $\begin{array}{l}\text { Formação Inicial de } \\
\text { Professores }\end{array}$ \\
\hline $\begin{array}{l}\text { 27-Agroecologia e Ensino de Ciências: } \\
\text { desafios e tensões na Educação do } \\
\text { Campo }\end{array}$ & 2017 & GAIA, M. C. de M. & Educação Ambiental \\
\hline $\begin{array}{l}\text { 28-Abordagem de temas: limites e } \\
\text { potencialidades em uma escola do } \\
\text { campo }\end{array}$ & 2017 & ALBERTON, J. et al. & $\begin{array}{l}\text { Processos de Ensino- } \\
\text { Aprendizagem }\end{array}$ \\
\hline $\begin{array}{l}\text { 29-Educação do Campo e Ensino de } \\
\text { Ciências: Contribuições da Perspectiva } \\
\text { Freireana para o Trabalho Docente }\end{array}$ & 2017 & $\begin{array}{c}\text { GONÇALVES, M. M.; BRICK, } \\
\text { E. M. }\end{array}$ & $\begin{array}{l}\text { Processos de Ensino- } \\
\text { Aprendizagem }\end{array}$ \\
\hline $\begin{array}{l}\text { 30-Formação de Educadores para } \\
\text { escolas do Campo e a possibilidade do } \\
\text { conhecimento crítico }\end{array}$ & 2017 & GOMES, A. T.; CEOLIN, T. & $\begin{array}{l}\text { Formação Inicial de } \\
\text { Professores }\end{array}$ \\
\hline $\begin{array}{l}\text { 31-Ciência e Tecnologia: uma análise } \\
\text { das compreensões de licenciandos em } \\
\text { Educação do Campo }\end{array}$ & 2017 & $\begin{array}{l}\text { OLIVEIRA, R. P.; } \\
\text { PRYBYCIEM, M. M.; } \\
\text { MÜNCHEN, S. }\end{array}$ & $\begin{array}{l}\text { Ciência tecnologia e } \\
\text { Sociedade }\end{array}$ \\
\hline $\begin{array}{c}\text { 32-Educação em Ciências e a Educação } \\
\text { do Campo: relações possíveis na } \\
\text { formação de professores da UFG - } \\
\text { Regional Goiás }\end{array}$ & 2017 & CARDOSO, E. C. de F. et al. & $\begin{array}{l}\text { Formação Inicial de } \\
\text { Professores }\end{array}$ \\
\hline $\begin{array}{l}\text { 33-Investigação temática em uma escola } \\
\text { do campo do município de Uberaba- } \\
\text { MG: identificando situação limite para o } \\
\text { estudo da biodiversidade }\end{array}$ & 2017 & $\begin{array}{l}\text { SANTOS, C. M. dos.; KATO, } \\
\text { D. S.; FRANCO, R. A. G. }\end{array}$ & $\begin{array}{l}\text { Processos de Ensino- } \\
\text { Aprendizagem }\end{array}$ \\
\hline $\begin{array}{l}\text { 34-Diálogos de Saberes na Educação do } \\
\text { Campo: observando os saberes } \\
\text { etnopedológicos em Cerro Azul (PR) }\end{array}$ & 2017 & BUENO, O. T. M. et al. & Educação Ambiental \\
\hline
\end{tabular}

A Figura 1 contempla número de artigos por instituição de origem. Considerouse importante identificar as universidades que mais desenvolvem pesquisas na Educação do Campo. 


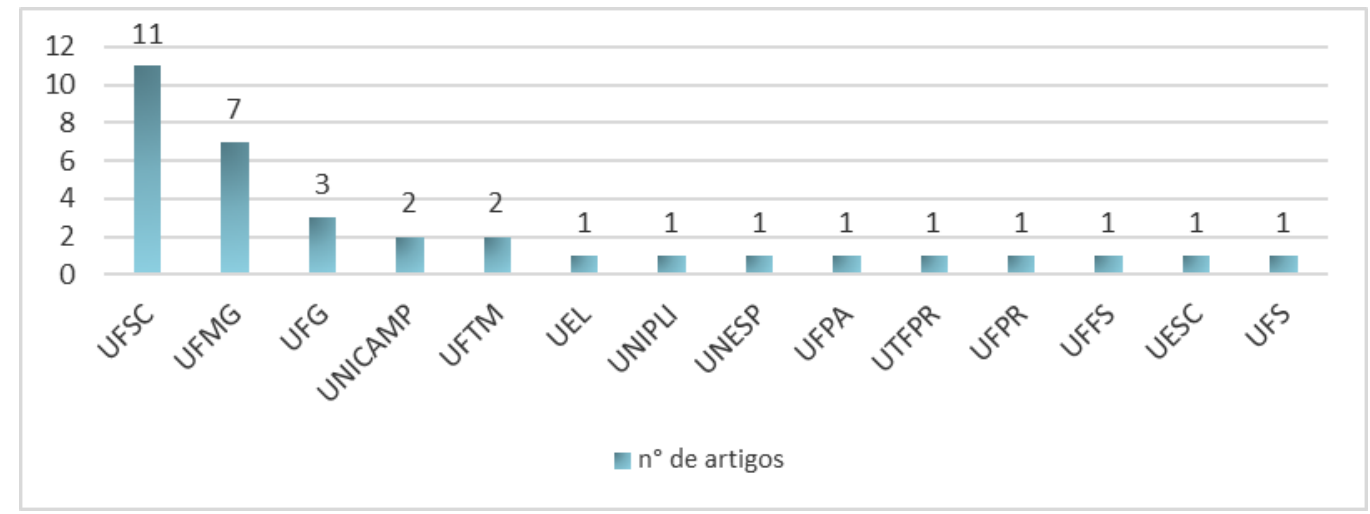

Figura 1 - Número de artigos por instituição de origem

Por meio da análise da Figura 1, percebe-se que 11 artigos (32,3\%) foram desenvolvidos na Universidade Federal de Santa Catarina. Suas publicações estão nas edições do ENPEC de 2009, 2011, 2013, 2015 e 2017. A Universidade Federal de Minas Gerais também tiveram um número expressivo (20,58\%) de trabalhos publicados nas edições do ENPEC de 2009, 2011, 2013, 2015 e 2017. Além disso, foram encontradas pesquisas realizadas pelas universidades dos estados de: Sergipe, Pará, Minas Gerais, Goiás, São Paulo, Rio de Janeiro, Paraná, Rio Grande do Sul.

Infere-se que esses resultados podem estar relacionados com o tempo de oferta dos cursos da Educação do Campo nessas universidades. Desta forma, elas veem desenvolvendo pesquisas neste campo de estudo há mais tempo. Como por exemplo, o curso de Licenciatura em Educação do Campo da Universidade Federal de Santa Catarina (UFSC) foi regulamentado em maio de 2008, sendo constituído no Centro de Ciências da Educação (CED) e integrando às atividades do Instituto de Educação do Campo e Desenvolvimento Territorial Sustentável (Instituto EDUCAMPO). Desde sua origem o curso tem estabelecido parcerias junto às organizações e Movimentos Sociais do Campo do Estado de Santa Catarina (BRASIL, 2009). O curso de Licenciatura em Educação do Campo da Universidade Federal de Minas Gerais (UFMG) começou a ser ofertado em 2009. A instituição mantém, desde 2005, o curso de Pedagogia da Terra, com o apoio do Ministério da Educação. A criação da nova graduação foi possível após a adesão da UFMG ao Plano de Reestruturação e Expansão das Universidades (REUNI), programa do governo federal lançado no ano 2007 (BRASIL, 2008). 


\subsection{Categoria: Aspectos metodológicos}

Em relação aos aspectos metodológicos, foram consideradas as seguintes categorias: a) Natureza da pesquisa; b) abordagem da pesquisa; c) nível de ensino. $\mathrm{O}$ Quadro 2 apresenta a síntese dos resultados.

Quadro 2 - Resultados dos aspectos metodológicos dos artigos analisados.

\begin{tabular}{|c|c|c|}
\hline & Frequência & Porcentagem (\%) \\
\hline \multicolumn{3}{|c|}{ Natureza da Pesquisa } \\
\hline Teórico & 15 & 44,11 \\
\hline Empírico & 19 & 55,88 \\
\hline Qualitativa & Abordagem da Pesquisa \\
\hline Quantitativa & 29 & 85,29 \\
\hline Mista & 0 & 0 \\
\hline \multicolumn{3}{|c|}{ Nível de ensino } \\
\hline Ensino Fundamental & 6 & 14,70 \\
\hline Ensino Médio & 2 & 5,88 \\
\hline Ensino Superior & 26 & 76,47 \\
\hline
\end{tabular}

A análise do Quadro 2 demonstra que 44,11\% dos artigos abordam pesquisas de cunho teórico. Essas pesquisas se estruturam dentro de um quadro teórico que visa apresentar e fundamentar os conceitos científicos trabalhados na educação do campo.

A maior parte dos trabalhos possui abordagem empírica, totalizando 55,88\%, cujas fontes de dados foram experimentos, questionário, entrevistas, exercícios e relatórios. Segundo Gerhardte Silveira (2009), esse tipo de abordagem metodológica objetiva a comprovação prática de um determinado fenômeno em estudo, por intermédio de experimentos ou observação para a coleta de dados.

Observou-se que muitas pesquisas empíricas se dedicaram em investigar as implicações pedagógicas da utilização dos pressupostos freireanos nos processos de ensino e aprendizagem para a Educação do campo. No estudo de Gonçalves e Brick (2017), por exemplo, foi realizado um levantamento de dados por meio de entrevistas, com vistas a investigar a realidade, reconhecendo o contexto social, histórico, econômico e cultural vivenciado pelos sujeitos e seus familiares. Após a análise dos 
dados coletados foi possível identificar temáticas que eram relevantes para a comunidade escolar, ou seja, emergiu-se o tema gerador.

A utilização do tema gerador, bem como a construção de programas escolares tendo como ponto de partida esse tema, é uma proposta pedagógica planeada na capacidade de compreender o fazer, o pensar, o agir, o refletir, levando em consideração a realidade e o contexto social em que os sujeitos estão inseridos, bem como suas relações entre situações individuais, históricas e sociais, favorecendo a discussão, interpretação, compreensão, representação e transformação dessa realidade (DELIZOICOV, ANGOTTI e PERNAMBUCO, 2009).

Quanto à natureza das pesquisas, há predominância (85\%) de investigações de caráter qualitativo. Nas últimas duas décadas, as pesquisas qualitativas se intensificaram no ensino das Ciências para todas as modalidades e umas das razões, segundo Neri de Souza (2006), encontra-se nas especificidades dessa área, que exige uma abordagem mais holística e interpretativa de suas problemáticas. Nenhum dos artigos analisados desenvolveu uma abordagem de cunho quantitativo. Esse resultado corrobora com as concepções de Lüdke e André (1986), na afirmação de que a abordagem quantitativa por si só não explica a complexa realidade do fenômeno educacional. Não há como prever, manipular, nem controlar as variáveis encontradas dentro do contexto escolar. Ou seja, a pesquisa educacional, segundo, Gallagher (2002) não possui enfoque somente no mundo físico, químico ou biológico, mas principalmente no mundo social e comportamental, em que as variações contextuais possuem um papel fundamental.

Observou-se uma expressiva quantidade de artigos voltados para o Ensino Superior, totalizando 76,47\%. Desta forma, infere-se que existe uma elevada preocupação com a formação de professores para a Educação do Campo. Esses resultados corroboram com Cardoso et al. (2017) ao enaltecerem que a Educação do Campo prioriza a formação docente pautada na compreensão dos sujeitos do campo, em que os componentes curriculares estejam intimamente interligados com a realidade dos sujeitos e com essa formação estes consigam transformar a realidade em que vivem. A formação de educadores para campo deve ser capaz de promover profunda articulação entre a escola e a comunidade, construindo habilidades necessárias para que estes 
futuros educadores possam internalizar as condições de interpretação das relações da escola com a vida.

Em relação ao Ensino Fundamental foram encontrados 17,64\% dos trabalhos e apenas 5,88\% dos trabalhos são voltados para Ensino Médio. Infere-se desse resultado que a maioria das pesquisas desenvolvidas no contexto da Educação do Campo estão voltadas para a formação de professores, ou seja, para ensino Superior. Desta forma destaca-se a importância de pesquisas que investiguem os processos de ensino e aprendizagem para os níveis de ensinos supracitados.

\subsection{Categoria: Temática de investigação do artigo}

A figura 2, ilustra as 6 temáticas de investigação apresentadas nos artigos, as quais são o foco desta pesquisa.

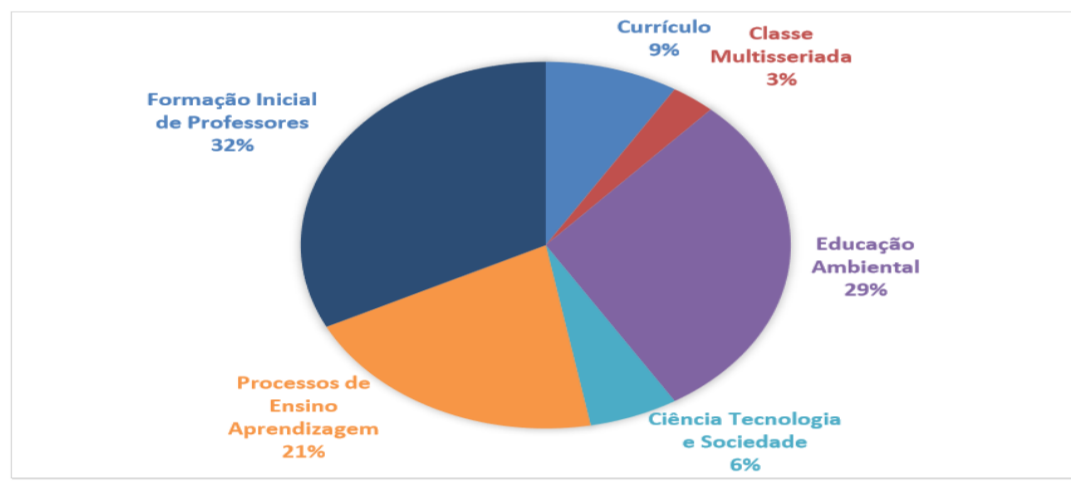

Figura 2 - Distribuição dos artigos quanto á Temática

A Figura 2 demonstra o percentual da distribuição dos trabalhos de acordo com a temática de investigação abordada no artigo. Após a análise, os trabalhos foram agrupados nas temáticas: Formação Inicial de Professores, Currículo, Classe Multisseriada, Educação Ambiental, Ciência Tecnologia e Sociedade e Processos de Ensino Aprendizagem.

Com o intuito de facilitar a compreensão dos resultados, será utilizado as numerações de 1 a 34 apresentadas no Quadro 1 para as indicações dos artigos analisados. 
Diante disso, é possível observar que $32 \%$ dos trabalhos desenvolvem suas pesquisas relacionadas com "Formação Inicial de Professores". Identificados nos artigos: 4, 7, 10, 12, 17, 19, 20, 25, 26. Conforme já mencionado, existe uma preocupação com a formação inicial de educadores do campo, o que implica, segundo Molina (2010) um desafio aos sujeitos educativos, o desafio de se reconhecer e de se questionar como sujeitos da história, produtores de conhecimento, valores, ação e cultura. Por isso a necessidade de uma formação e metodologias especificas, pensadas a partir da perspectiva da Educação do Campo (e não da educação rural), e que leve em consideração as especificidades de que esta modalidade de ensino necessita.

Também é possível mencionar que à temática "Educação Ambiental" obteve um quantitativo de $29 \%$ dos trabalhos publicados, entre eles estão: 2, 5, 9, 11, 14 15, 23, 24, 27. Carcaioli e Tonso (2015) defendem a importância de discutir a Educação Ambiental dentro do contexto da Educação do Campo, pois resgata valores basilares para uma atuação mais responsável frente aos problemas ambientais, bem como superação das desigualdades sociais, dominação da natureza e da degradação do ambiente em que vivemos.

A temática "Processos de Ensino Aprendizagem" também foi bastante discutida, alcançando um percentual de $21 \%$, contemplando os artigos: 6, 13, 16, 21, 28, 29, 33.

Observou-se que a maior parte dos artigos analisados, referentes à temática em questão, abordaram os processos de ensino e aprendizagem pautados nos pressupostos defendidos por Paulo Freire. Esses resultados estão em concordância com os fundamentos que sustentam os anseios da Educação do Campo, pois Paulo Freire é considerado um educador popular progressista, sendo criador e difusor de uma pedagogia crítico transformadora. Seus pressupostos vão contra as políticas neoliberais, mecanicistas e tecnicistas de educação, que privilegiam a formação de indivíduos não críticos, incapazes de interagirem entre si e com o mundo para buscar soluções para o enfrentamento dos problemas existentes. Para Paulo Freire, o processo educacional deve ser transformador, ou seja, favorecer com que os indivíduos interajam com os aspectos sociais, políticos e econômicos que os rodeiam. 
Nessa perspectiva, segundo Delizoicov, Angotti e Pernambuco (2009), ao contrário de uma educação que enaltece a memorização, a fragmentação e é desconectada da realidade, a concepção educacional freireana está pautada na conscientização, problematização e dialogicidade em torno da realidade e contradições vivenciadas pelos educandos com o intuito de estimular a participação responsável dos indivíduos nos processos culturais, sociais, políticos e econômicos do mundo em que vivem.

Os outros trabalhos obtiveram um somatório de $18 \%$, sendo que estes se dividem em três temáticas: Classe multisseriada: artigo 1; Currículo: artigos 3, 18, 22; Ciência Tecnologia e Sociedade: artigos 8, 31.

\subsection{Categoria: Resultados das pesquisas}

Em relação aos principais resultados apresentados nos artigos, os mesmos foram sistematizados em três temáticas de investigação que tiveram maior incidência durante os ENPEC's: Processos de Ensino Aprendizagem, Formação inicial de professores e Educação Ambiental.

Em relação ao "Processo de Ensino Aprendizagem" e "Formação Inicial de Professores" foram identificados dezesseis artigos, dentre eles $30 \%$ estão relacionados com as abordagens referentes à perspectiva Freireana para o Ensino de Ciências. Ressalta-se que essa abordagem vem sendo estudada por vários autores, como exemplo: Delizoicov (1991); Pernambuco (1994); Pontuschka (2001); Silva (2004); Stuani (2010); Lindemann (2010); Coelho (2010); Torres (2010). Segundo Gehlen et al. (2014), a Abordagem Temática constitui em uma perspectiva de inovação curricular onde os conteúdos podem ser articulados com a realidade e experiência dos sujeitos do campo, valorizando os saberes dos estudantes, onde tem-se um Tema Gerador.

Para Delizoicov (1982):

O tema gerador gerará um conteúdo programático a ser estudado e debatido, não só como um conteúdo insípido e através do qual se pretende iniciar o aluno ao raciocínio científico; não um conteúdo determinado a partir da ordenação dos livros textos e dos programas oficiais, mas como um dos instrumentos que tornam possível ao aluno uma compreensão do seu meio natural e social (DELIZOICOV, 1982 p.11). 
Os artigos que trouxeram a Abordagem Freireana sinalizam que:

[...] o planejamento de disciplinas com foco em temáticas comuns- neste caso, a temática energia- é uma proposta interessante e que pode auxiliar aos alunos a relacionarem conhecimentos de diferentes áreas da ciência (Artigo 10, p.10).

[...] Entendemos que as diferentes possibilidades de abordagem temática nos cursos de Licenciatura em Educação do Campo e Licenciatura Intercultural indígena são legítimas. No entanto, compreendemos que a investigação temática pautada nos temas geradores possui um potencial de ser desenvolvida nestes cursos em razão de seu modo de organização que tem a pedagogia da alternância como uma possibilidade de aproximação e estudo da realidade dos estudantes e a formação por área de conhecimento e não disciplinar (Artigo 19 p.6).

[...] Ao invés dos conteúdos determinarem o trabalho em sala de aula, os questionamentos suscitados pelo tema gerador é que pautaram esse trabalho. Assim, o trabalho com o tema gerador contribui para revisitar e aprofundar os conceitos de ácidos e bases e permite avançar na compreensão das contradições sociais intrínsecas ao tema (Artigo 29, p.8).

Esses resultados ressaltam a importância da utilização dos temas geradores na Educação do Campo, percebeu-se que a utilização destes, contribui não apenas para questões formais do Ensino de Ciências, mas também para a apropriação de conhecimentos científicos como princípios que proporcionam aprimorar o entendimento da realidade, podendo construir possibilidades para resolução de problemáticas. Esses aspectos corroboram com Halmenschlager et al. (2017) ao afirmar que a relação entre os temas e contextos foi possível viabilizar uma visão educativa comprometida com a transformação da realidade.

Em relação à temática de investigação "Educação Ambiental” foram selecionados dez artigos. Estes estão relacionados, principalmente, com a Agroecologia, um tema de forte impacto para a Educação do Campo. Segundo Caporal (2009), Agroecologia é reconhecida como uma nova ciência em construção, das quais os conceitos e bases epistemológicas sugerem concepções sobre a viabilidade de modificação das técnicas de uso e manejo dos recursos naturais, de forma a expandir a inclusão social, diminuir danos ambientais e garantir a segurança alimentar e nutricional. Diante disso, os artigos que trouxeram o tema Agroecologia enfatizam que:

A Agroecologia pode servir de suporte para escolhas dos conteúdos escolares, sendo um caminho político e ideológico para criação do campo que precisamos. Uma alternativa pedagógica de conectar o ensino a realidade, de 
concretizar a relação da escola com a vivência dos estudantes (Artigo 27, p. $6)$.

A Agroecologia se fortalece a partir de diferentes ciências (ecologia, biologia, agronomia, química, antropologia), ou seja, ela é capaz de ser aplicada de forma transversal e multidisciplinar, já que permite a aprendizagem de diferentes variáveis: econômicas, sociais, ambientais. Além disso, deve haver o diálogo dos impactos desse ensino na vivência dos sujeitos do campo e também deve haver a relação ensino de Ciências e Agroecologia na formação de docentes em cursos de Licenciaturas em Educação do Campo, para que estas transformações aconteçam de fato, nas escolas do campo (Artigo 24, p. 7).

Desta forma conclui-se que os trabalhos apresentados, reforçam a ideia de que a agroecologia é um tema relevante para Educação do Campo, apontando a necessidade e difusão de novos conhecimentos para formação de sujeitos que compreendam uma nova relação entre o homem e a natureza, na busca da sustentabilidade socioambiental. Neste sentido, a Educação do Campo passa a assumir um papel de destaque, por meios de processos educativos, difusão e reflexões para evolução de novos princípios e práticas nas interações entre os sujeitos e o ambiente.

\section{CONCLUSÃO}

Neste estudo, compreendemos que apesar da Educação do Campo possuir uma trajetória relativamente atual, podemos acompanhar as discussões acerca do tema Educação do Campo em um dos eventos de maior destaque para o Ensino de Ciências, que é o ENPEC. É perceptível a relevância desse espaço nas discussões do Ensino de Ciências, com temas importantes para Educação do Campo, articulada às necessidades e especificidades dos camponeses.

As análises das produções sobre abordagem de temas de investigação no Ensino de Ciências relacionadas à Educação do Campo indicam que há uma predominância da Abordagem Temática Freireana nos processos de ensino e aprendizagem para essa modalidade de ensino. Além disso, a formação inicial de professores para a Educação do campo e a Educação ambiental também obtiveram representatividade nos estudos analisados. 
Eventos como ENPEC, contribuem significativamente para discussões sobre o processo de ensino e aprendizagem que se consolidam nestes espaços de interação para a troca de experiências e exposição de trabalhos científicos, produzindo efeitos positivos no desenvolvimento da Educação do Campo.

Enfim, espera-se que os dados deste trabalho contribuam para que os docentes obtenham referenciais sobre metodologias diferenciadas para auxilio em suas aulas de Ciências, uma vez que com a análise dos artigos podemos delinear os principais temas abordados na Educação do Campo.

\section{REFERÊNCIAS}

BRASIL. UNIVERSIDADE FEDERAL DE SANTA CATARINA. Projeto Pedagógico do Curso de Licenciatura em Educação do Campo. Florianópolis, 2009. Disponível em: <http://licenciatura.educampo.ufsc.br/files/2014/08/PPP-LEdoC.pdf>. Acesso em: Out 2018.

BRASIL. UNIVERSIDADE FEDERAL DE MINAS GERAIS. Minas Gerais, 2008. Disponível em: <www.ufmg.br/online/arquivos/anexos/LICENCIATURA\%20DO\%20CAMPO.pdf> Acesso em: Out 2018.

BRASIL. Ministério da Educação e Cultura. Diretrizes Operacionais para a Educação Básica nas Escolas do Campo. Brasília, MEC/SECAD, 2002.

BRASIL. Ministério da Educação e Cultura. Lei de Diretrizes e Bases da Educação Nacional - LDB. Lei nº 9.394 de dezembro de 1996.

CAldart, R. S., CERIOLI, P. R., KOlling, E. J. Por uma Educação do Campo: Educação do Campo Identidade e Políticas Públicas. n 4. Brasília, DF, 2002.

CALDART, R. S. Elementos para a construção do projeto político pedagógico da Educação do Campo. In: PARANÁ. Secretaria de Estado da Educação. Superintendência de Educação. Departamento de Ensino Fundamental. Cadernos Temáticos da Educação do Campo. Curitiba-PR. SEED, 2005

CAPORAL, F. R.; Agroecologia: uma nova ciência para apoiar a transição a agriculturas mais sustentáveis. In: CAPORAL, F. R.(Org.) Agroecologia: uma ciência do campo da complexidade. Brasília: DF, 2009. p. 9-46 
CARCAIOLI,G. F; TONSO, S. O protagonismo dos camponeses e o Ensino de Ciências nas escolas do campo In: Atas do X Encontro Nacional de Pesquisa em Educação em Ciências. Águas de Lindóia - SP, 2015.

COELHO, J.C. Processos formativos na direção da educação Transformadora: temasdobradiça como contribuição para abordagem temática. Tese. PPGECT/UFSC, Florianópolis, 2010.

COSTA, S. S. C., e MOREIRA, J. P. Resolução de problemas I: diferenças entre novatos e especialistas. Investigações em Ensino de Ciências, 1996.

DELIZOICOV, D. Conhecimento, tensões e transições. Tese. FAE/USP: São Paulo, 1991.

DELIZOICOV, D. Concepção Problematizadora do Ensino de Ciências na Educação Formal. Dissertação de Mestrado. FE/USP, São Paulo, 1982.

DELizOICOV, D.; ANGOTTI, J. A. P.; PERnAMBUCO, M. M. C. A. Ensino de ciências: fundamentos e métodos. 3. ed. São Paulo: Cortez, 2009.

DEMO, P. Metodologia do conhecimento científico. São Paulo, Atlas, 2000.

DESLAURIERS, J.P. Recherche qualítative- Guide pratique. Montreal: McGrawHill, 1991.

ENISWELER, K.C.; KLIEMANN, C.R.M.; STRIEDER, D.M. O ensino de Ciências na educação do campo: uma pesquisa em dissertações e teses. In: Seminário Nacional Interdisciplinar em Experiências Educativas. 5, 2015, Paraná. Anais. Paraná: Unioeste,2015. p. 763-774.

FERNANDES, L. S., e CAMPOS, A. F. Tendências de pesquisa sobre a resolução de problemas em Química. Revista Electrónica de Enseñanza de las Ciências, 2017.

FREIRE, P. Pedagogia do Oprimido. Rio de Janeiro: Paz e Terra, 1987. Educação e mudança, v. 18, 2014.

FREITAS, L. C de. A Escola Única do Trabalho: explorando os caminhos de sua construção. In: CALDART, R. S. (Org.) Caminhos para transformação da Escola 1: Reflexões desde práticas da licenciatura em Educação do Campo. $1^{\mathrm{a}}$ ed. São Paulo: Expressão Popular, 2010. p. 155-175.

GEHLEN, S. T.; STRIEDER, R. B.; CARAMELlO, G. W.; FEISTEL, R. A. B.; HALMENSCHLAGER, K. R. A inserção da Abordagem Temática em cursos de Licenciatura em Física em instituições de Ensino Superior. Investigações em Ensino de Ciências, v.19, n.1, 217-238, 2014. 
GERHARDT, T. E.; SILVEIRA, D. T. Métodos de pesquisa.1 ${ }^{a}$ Ed. UFGRS, 2009.

GIL, A. C. Como elaborar projetos de pesquisa. 4ed. São Paulo: Atlas, 2009.

GONÇALVES, M. M.; BRICK, E. M. Educação do Campo e Ensino de Ciências: Contribuições da Perspectiva Freireana para o Trabalho Docente. In: Atas do XI Encontro Nacional de Pesquisa em Educação em Ciências. Florianópolis - SC, 2017.

GÜNTHER, H. Pesquisa qualitativa versus pesquisa quantitativa: esta é a questão? Psicologia: teoria e pesquisa, Brasília, v. 22, n. 2, pp. 201-210, Mai./Ago. 2006.

HALMENSCHLAGER, K. R.; FERNANDES, C. dos S.; CAMILLO, J.; BRICK, E. M. Abordagem de temas no Ensino de Ciências e Matemática: um olhar para produções relacionadas à Educação do Campo. In: Atas do XI Encontro Nacional de Pesquisa em Educação em Ciências. Florianópolis - SC, 2017.

HOPPEN, N., e MEIRELLES, F. S. Sistemas de Informação: um panorama da pesquisa científica entre 1990 e 2003. Revista de Administração de Empresas, 2005.

LINDEMANN, R. H. Ensino de química em escolas do campo com proposta agroecológica: contribuições a partir da perspectiva freireana de educação. Tese. PPGECT/UFSC, Florianópolis, 2010.

LOPES, J. M. V.; LOURENÇO, M. E. R. de. Apontamentos acerca da Educação do Campo. In: VI Seminário Nacional de Formação de Professores/UFSM. Santa Maria, 2015.

LÜDKE, M., e ANDRÉ, M. E. D. A. Pesquisa em Educação: Abordagens Qualitativas, São Paulo, SP, 23-26, 1986.

LUCAS, R. E. A. Educação formal/rural permeando as relações do campo: um estudo de caso na Escola Estadual de Tempo Integral de Ensino Fundamental Cândida Silveira Haubman-Arroio Grande, RS. 2008. 357. Tese (Doutorado em Agronomia) -Programa de Pós-Graduação em Agronomia, Universidade Federal de Pelotas, Pelotas, 2008.

MARCONI, M. de A.; LAKATOS, E. M. Técnicas de pesquisa. 4. ed. São Paulo: Atlas, 1999.

MOLINA, M. C. Educação do campo e pesquisa II: questões para reflexão. In: MOLINA, M. C. (Org.) Educação do Campo e Pesquisa: questões para reflexão. Brasília - DF: MDA/MEC, 2010. p. 7-13

PERNAMBUCO, M.M.C. Educação e escola como movimento. Tese de Doutorado. FE/USP, São Paulo, 1994. 
PERRENOUD, P; THURLER, M. G.; MACEDO, L. de; MACHADO, N. J.; ALLESSANDRINI, C. D. As competências para ensinar no século XXI: a formação dos professores e o desafio da avaliação. Artmed Editora, 2007.

PONTUSCHKA, N. N. (org). Ousadia no diálogo. $3^{\text {a }}$ ed. São Paulo: Loyola, 2001.

ROSA, D. S. da; CAETANO, M. R.- Da educação rural à educação do campo: uma trajetória... Seus desafios e suas perspectivas. Revista Colóquio, v. 6, n. 1-2, p. 21-34, 2008.

SILVA, A. F. G. A construção do currículo na perspectiva popular crítica: das falas significativas às práticas contextualizadas. Tese. PUC/SP: São Paulo, 2004.

SOUZA, I. P. F. de; REIS, E. dos S. Educação para a convivência com o Semi-árido: reencantando a educação a partir das experiências de Canudos, Uauá e Curaçá. São Paulo: Petrópolis, 2003.

STUANI, G. M. A construção curricular popular crítica no ensino de ciências naturais e suas implicações na prática docente. Dissertação de Mestrado. PPGECT/UFSC. Florianópolis, 2010.

TORRES, J. R. A Abordagem Temática Freireana: Educação Ambiental Crítico Transformadora. In: Torres, Juliana Rezende. Educação Ambiental CríticoTransformadora e Abordagem Temática Freireana. Tese. PPGECT/UFSC, Florianópolis, p. 237-306, 2010.

ANEXO A- Roteiro de Análise dos artigos

Critério: Caracterização

Título do Artigo:

Ano:

Instituição:

Critério: Aspectos metodológicos

Natureza da pesquisa: ( ) teórica ( ) empírica

Abordagem da pesquisa: ( ) qualitativa ( ) quantitativa ( ) mista

Nível de ensino: ( ) Ensino Fundamental ( ) Ensino Médio ( ) Ensino Superior.

Critério: Temática do artigo

Indicar Temática do artigo:

Indícios 


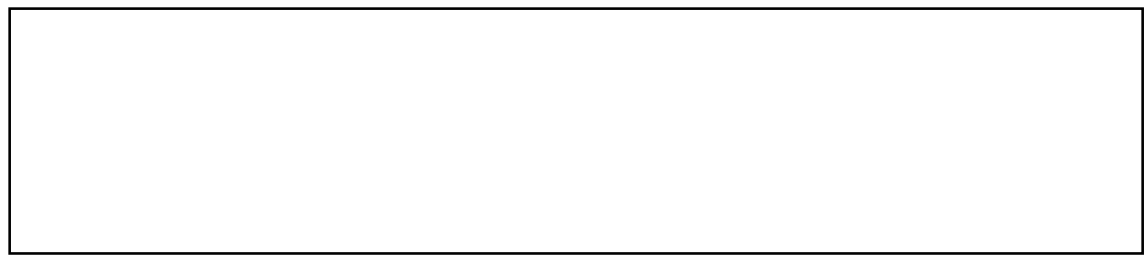

Critério: Resultados

Principais resultados

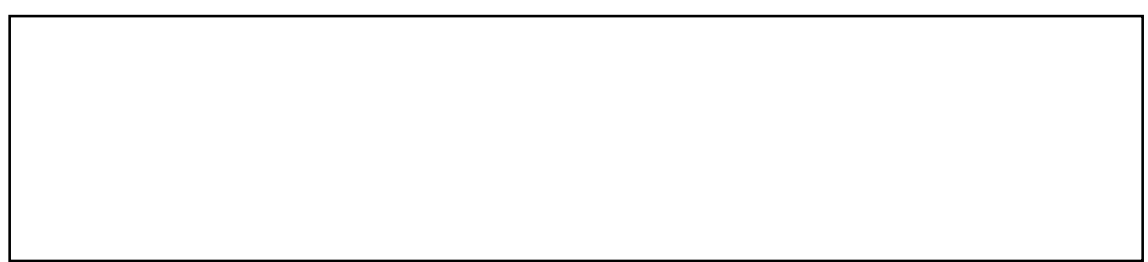

Recebido em: 26/03/2019 